\title{
Research Article \\ Electronic Controlling on Nanotribological Properties of a Textured Surface by Laser Processing
}

\author{
Haifeng Yang, ${ }^{1,2}$ Kun Liu, ${ }^{1}$ Yanqing Wang, ${ }^{3}$ Hao Liu, ${ }^{1}$ Jiaxiang Man, ${ }^{1}$ and Bo Sun ${ }^{1}$ \\ ${ }^{1}$ College of Mechanical \& Electrical Engineering, China University of Mining and Technology, Xuzhou, Jiangsu 221116, China \\ ${ }^{2}$ Jiangsu Key Laboratory of Mine Mechanical and Electrical Equipment, China University of Mining and Technology, Xuzhou \\ 221116, China \\ ${ }^{3}$ School of Materials Science and Engineering, China University of Mining and Technology, Xuzhou 221116, China
}

Correspondence should be addressed to Kun Liu; liuk1995@163.com

Received 11 July 2017; Accepted 14 August 2017; Published 6 September 2017

Academic Editor: Xun $\mathrm{Hu}$

Copyright (c) 2017 Haifeng Yang et al. This is an open access article distributed under the Creative Commons Attribution License, which permits unrestricted use, distribution, and reproduction in any medium, provided the original work is properly cited.

\begin{abstract}
The friction-reducing performance of surfaces with regular nanotextures is a key topic in surface engineering research. This paper presented a simple, easily controlled method for fabricating regular nanotextures on an electrodeposited Ni-Co alloy. The electronic controlling on the friction performance of a nanotexured surface was investigated by AFM. The results showed that the frictional force of a nanotexured surface can be controlled by an external electric field. Before laser processing, the friction initially increased with the bias voltage and then decreased after the bias voltage exceeded $1.0 \mathrm{~V}$. Its friction forces can be changed more than 2 times under the different external electric field. After laser processing, the trend of the frictional force was reversed and its friction forces changed more than 12 times for the laser-processed sample with $0.18 \mathrm{~J} / \mathrm{cm}^{2}$ laser power. The results also showed that the friction force decreased when using different nanotextures in an external electric field.
\end{abstract}

\section{Introduction}

In computing and MEMS areas, $\mathrm{Ni-Co}$ coating was widely applied in such devices as microforceps, micromirrors, and microswitches. Usually, these devices worked under an external electric field. However, the effect of this external electric field on the friction performance of Ni-Co coatings was rarely studied. Meanwhile, it can also be used in the controlling of the friction coefficient or maintaining its stability.

Through controlling the surface characteristics, an engineered surface can be made to deliver the desired functional performance [1]. Except for a wide range of other applications of laser technique [2-4], as an effective technique, it also was used to improving the coating performances [5-8]. Many researchers have investigated the laser processing technique about how to improve surface performance of alloy coatings [9-11]. Nowadays, methods such as moulding [12], electrochemical deposition [13, 14], and chemical vapor deposition [15] are used to produce artificial surfaces with particular textures. However, all of these methods fail to produce controllable textured surfaces. In recent years, many researchers have adopted new processes to fabricate textures on solid surfaces. Mo et al. fabricated the nanotexture on an $\mathrm{H}$-passivated Si surface by current-induced local anodic oxidation and investigated its nanotribological properties by colloidal probe $[16,17]$. The results indicated that the nanotextures exhibited low adhesion and greatly reduced the friction at a nanometric scale. Fang Liang investigated the friction and wear of a 45 \# steel surface textured by YAG laser and found that the coefficient of friction of a cross-grooved surface increased with decreasing texture span (i.e., width of pattern). The tribological properties of nanotextures on $\mathrm{Ni}$-Co coatings have not been extensively studied to date.

In recent years, many researchers have investigated the relationship between the nanotribological properties and external electric field at nanoscale in different domains. Park et al. found that the nanoscale friction properties of a $\mathrm{Si}$ (100) sample can be manipulated significantly by the simple application of a bias voltage [18]. They then observed a significant increase in friction under accumulation (forward bias) 


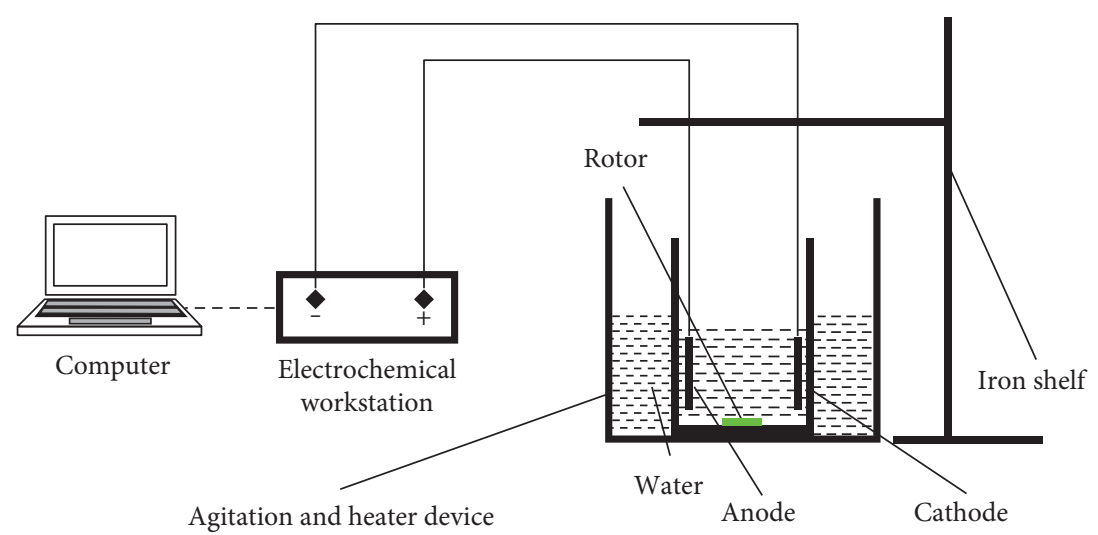

(a)

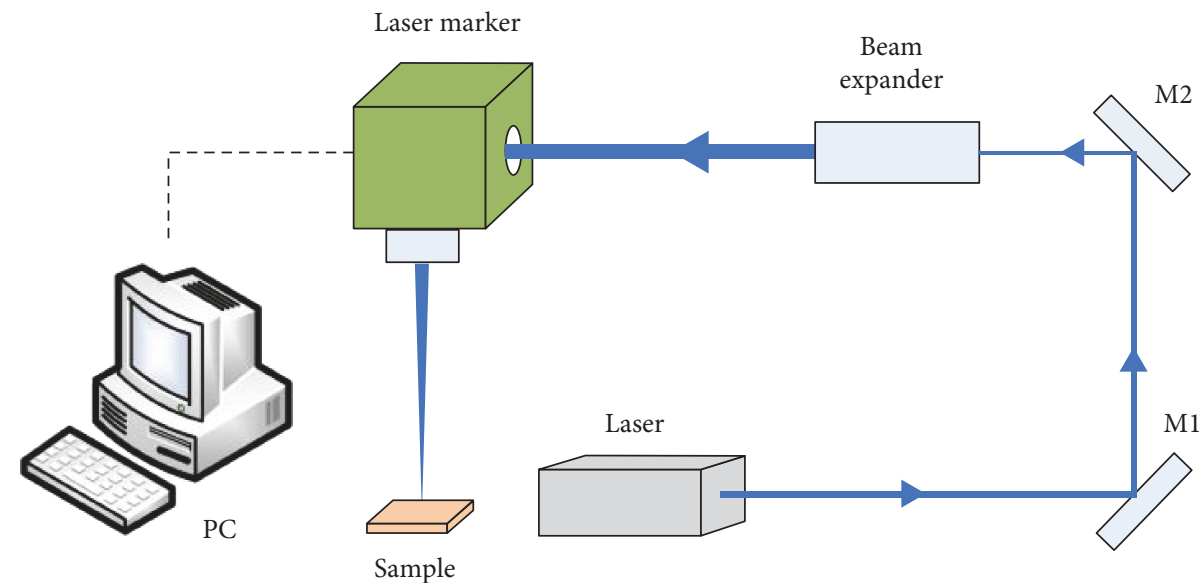

(b)

Figure 1: (a) Schematic of the electroplating setup. (b) Laser processing experimental system.

conditions with respect to depletion (reverse bias) conditions and established a model based on the force exerted by the trapped charges that quantified the experimental observations of excess friction, using a Pt-coated tip with a $50 \mathrm{~nm}$ radius in an AFM sliding against an n-type GaAs (100) substrate [19]. Liu et al. investigated the microtribological properties of Langmuir-Blodgett monolayer films in AC and DC electric fields [20]. They found that the friction and wear characteristics of Langmuir-Blodgett films could be controlled and improved by an external electric field. However, the influence of an external electric field on the friction properties of nanotexures on a $\mathrm{Ni}$-Co coating has not previously been studied.

Here, the nanotextures on the Ni-Co alloy coating surface were fabricated by the laser processing technique. The surface morphology and microstructure of the laser-processed region were characterized by SEM. Then, the nanotribological behavior of different nanotexured surfaces under external electrical field was investigated by FFM and AFM.

\section{Experiments}

2.1. Experimental Setup. The experimental setup for the electroplating is shown in Figure 1(a). A type of CHI660D electrochemical workstation was used to provide power supply.
TABLE 1: The composition of the electroplating bath solution and relevant processing parameters.

\begin{tabular}{lc}
\hline Composition & Content $/ \mathrm{gL}^{-1}$ \\
\hline Cobalt sulphate & 30 \\
Nickel sulphate & 250 \\
Nickel chloride & 40 \\
Boric acid & 35 \\
\hline Code position condition & 50 \\
\hline Temperature $\left({ }^{\circ} \mathrm{C}\right)$ & 3.5 to 4.5 \\
\hline
\end{tabular}

Figure 1(b) showed the laser processing experimental system for fabricating nanotextures on the electroplated $\mathrm{Ni}$-Co alloy coating surface. An ultraviolet laser (DSH-355-10, Photonics Industries, USA) with a working wavelength of $355 \mathrm{~nm}$ was used to process the specimen. The laser beam was completely reflected by two mirrors. The reflected beam was filled, collimated, and expanded by a beam expander. The beam expander could allow the high-frequency noise to be removed from the laser beam to provide a clean Gaussian profile and make the laser beam smaller after focusing. A computer-controlled laser marker was used to control the direction of the laser beam. 


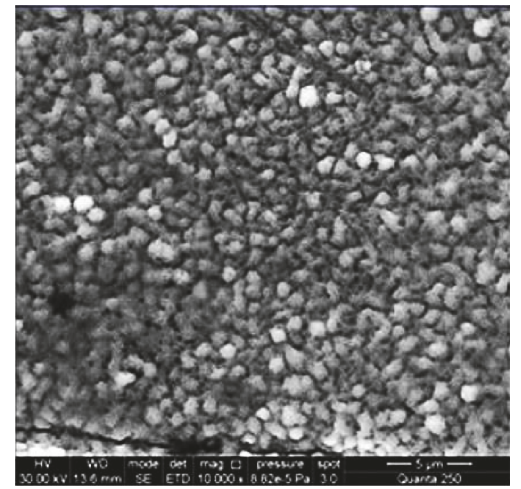

(a)

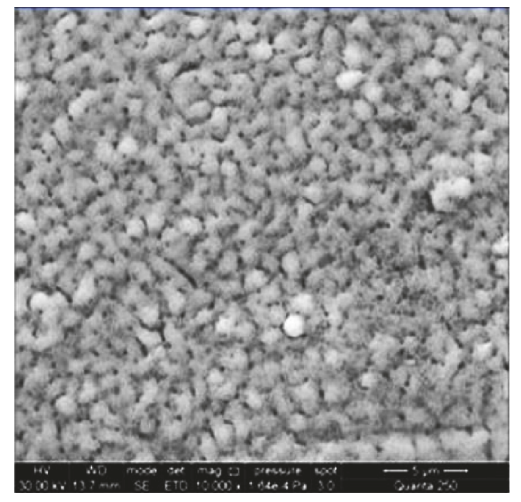

(d)

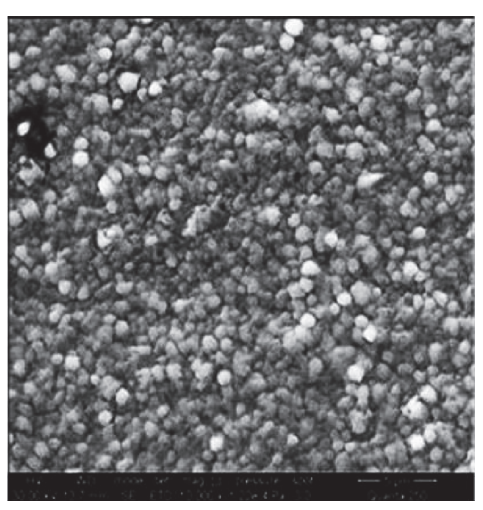

(b)

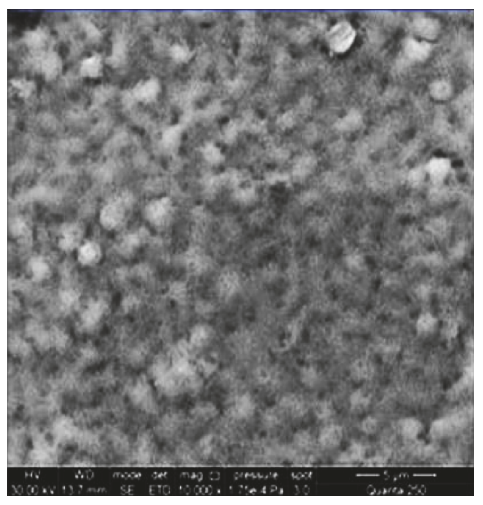

(e)

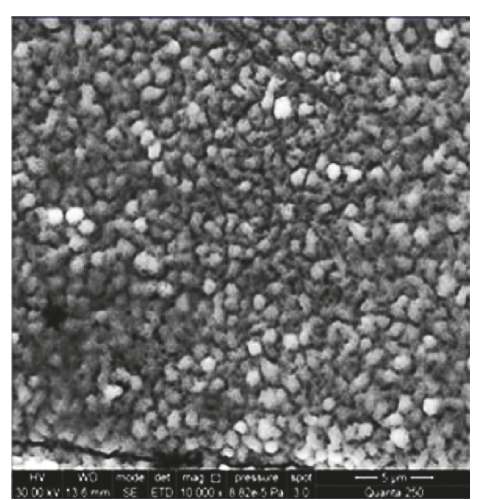

(c)

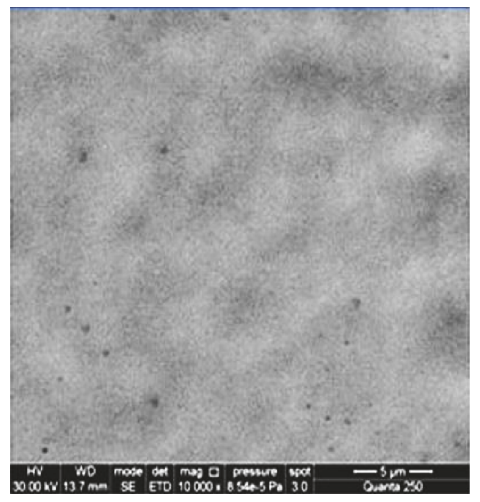

(f)

Figure 2: SEM images of Ni-Co alloy coating surface. (a) Unprocessed; laser processed at (b) $0.03 \mathrm{~J} / \mathrm{cm}^{2}$; (c) $0.05 \mathrm{~J} / \mathrm{cm}^{2}$; (d) $0.08 \mathrm{~J} / \mathrm{cm}^{2}$; (e) $0.18 \mathrm{~J} / \mathrm{cm}^{2}$; (f) $0.22 \mathrm{~J} / \mathrm{cm}^{2}$.

2.2. Experimental Method. Before the electroplating of Ni-Co alloy coating, the bath composition was prepared according to Table 1. To ensure that the composition of the bath was uniform, the electrolyte was subject to magnetic stirring for $20 \mathrm{~min}$ before the deposition process started. A nickel sample, of commercial-purity grade, measuring $80 \mathrm{~mm} \times 60 \mathrm{~mm} \times 2 \mathrm{~mm}$ was used as the anode, and a type 316L stainless steel specimen, measuring $20 \mathrm{~mm} \times$ $10 \mathrm{~mm} \times 2 \mathrm{~mm}$, was used as the cathode. The cathode was placed $30 \mathrm{~mm}$ from, and parallel to, the nickel when immersed in the bath. Before electroplating, the specimen was polished using 2000 grit and then degreased in acetone under ultrasonic vibration for $5 \mathrm{~min}$ and then pretreated in $1 \mathrm{~mol} / \mathrm{L} \mathrm{HCL}$ solution for $2 \mathrm{~min}$ at room temperature to remove the surface oxide scale.

Then, the electroplating was performed under direct current conditions with the current density of $25 \mathrm{~mA} / \mathrm{cm}^{2}$ and electroplating time of $20 \mathrm{~min}$. After electroplating, distilled water was used to wash the specimen. The specimen was tested after being dried at room temperature in air for several hours. The deposition thickness was about $8 \mu \mathrm{m}$. The surface morphology and microstructure of the coating were characterized by SEM.

After that, the laser processing experimental system was used to fabricate nanotextures on the electroplated $\mathrm{Ni}$-Co alloy coating. The laser power ranged from $0 \mathrm{~J} / \mathrm{cm}^{2}$ to $2 \mathrm{~J} / \mathrm{cm}^{2}$ at a scan speed of $25.4 \mathrm{~mm} / \mathrm{s}$ and line interval of $0.01 \mathrm{~mm}$. The SEM was used to analyze the effect of laser irradiation on the surface morphology and microstructure of the coating.

Lastly, the nanotribological behavior of the Ni-Co alloy coating in this electric field was measured by AFM/FFM (CSPM5500 electronics, Benyuan Nano-Instruments, China). The probe was coated with a conducting layer of $\mathrm{Au}$ film. The varying load $(0.1$ to $1.0 \mathrm{~V})$ and bias voltage $(0.0 \mathrm{~V}, 0.5 \mathrm{~V}, 1.0 \mathrm{~V}, 1.5 \mathrm{~V}$, and $2.0 \mathrm{~V})$ were applied between the probe and the sample.

\section{Results and Discussions}

3.1. Laser-Induced Nanotextures on the Ni-Co Alloy Coating. The laser power was varied to investigate the influence on the Ni-Co alloy coating. The laser power was increased from $0 \mathrm{~J} / \mathrm{cm}^{2}$ to $0.22 \mathrm{~J} / \mathrm{cm}^{2}$. Figure 2 shows the micrographs of the Ni-Co alloy surfaces after laser processing at $0 \mathrm{~J} / \mathrm{cm}^{2}$, $0.03 \mathrm{~J} / \mathrm{cm}^{2}, 0.05 \mathrm{~J} / \mathrm{cm}^{2}, 0.08 \mathrm{~J} / \mathrm{cm}^{2}, 0.18 \mathrm{~J} / \mathrm{cm}^{2}$, and $0.22 \mathrm{~J} / \mathrm{cm}^{2}$.

The morphology of the Ni-Co alloy coating before laser process was shown in Figure 2(a). Many irregular-sized microparticles and nanoprotrusions were observed. The average diameter of the grains was approximately $0.7 \mu \mathrm{m}$. The Co content in the coating accounted for $40 \%$ of its total mass. The roughness $R_{a}$ of the Ni-Co coating surface was approximately $25 \mathrm{~nm}$. After laser processing at $0.03 \mathrm{~J} /$ $\mathrm{cm}^{2}$, most of the irregular protrusions become half- 


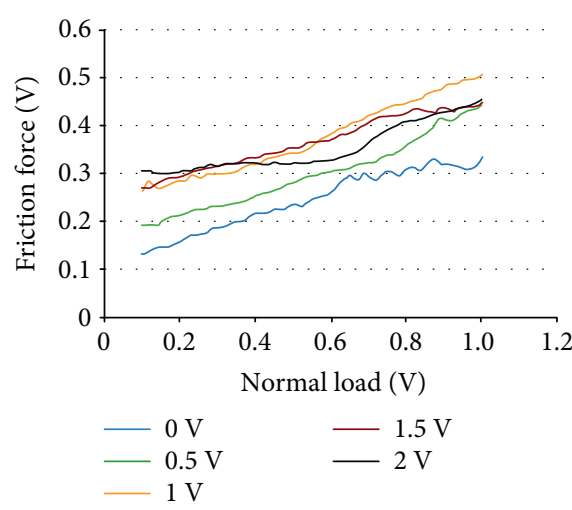

(a)

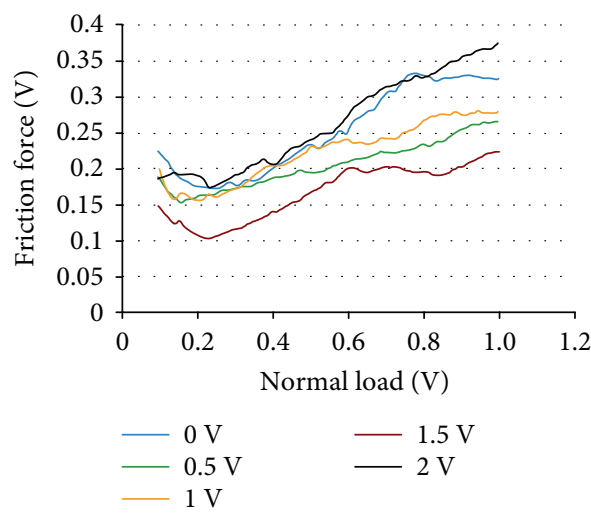

(c)

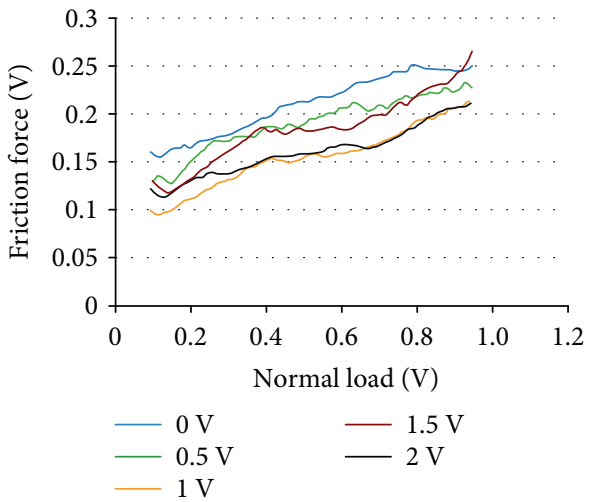

(b)

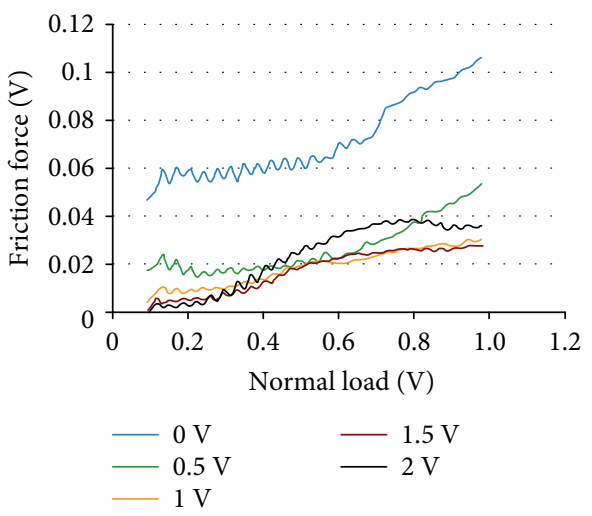

(d)

Figure 3: Frictional force versus normal load, from $0.1 \mathrm{~V}$ to $1.0 \mathrm{~V}$, with five bias voltages $(0 \mathrm{~V}, 0.5 \mathrm{~V}, 1 \mathrm{~V}, 1.5 \mathrm{~V}$, and $2 \mathrm{~V})$ for the four Ni-Co alloy coating surfaces. (a) unprocessed; laser processed at (b) $0.03 \mathrm{~J} / \mathrm{cm}^{2}$; (c) $0.05 \mathrm{~J} / \mathrm{cm}^{2}$; (d) $0.18 \mathrm{~J} / \mathrm{cm}^{2}$.

hemispherical and more regular and the surface morphology of the laser-processed area was also uneven (Figure 2(b)). With increase of laser power, the half-hemispherical nanoprotrusions grew uniformly and gradually became halfellipsoid structures. Besides, when the laser powers were 0.05 and $0.08 \mathrm{~J} / \mathrm{cm}^{2}$, the surface morphology of the laserprocessed area becomes flatter, as shown in Figures 2(c) and $2(\mathrm{~d})$. At $0.18 \mathrm{~J} / \mathrm{cm}^{2}$, the half-hemispherical nanoprotrusions continued to grow and began to reduce in number (Figure 2(e)). Figure 2(f) showed that the surface morphology of the laser-processed area had become relatively smooth at $0.22 \mathrm{~J} / \mathrm{cm}^{2}$ and the nanoprotrusions had completely disappeared.

Through these experiments, we concluded that the formation of regular nanoprotrusions was dependent on the power of the ultraviolet laser. Therefore, we can adjust the power of the ultraviolet laser for fabricating stable nanoprotrusions on the surface of the Ni-Co alloy coating. Koch et al. and Mannion et al. once proposed a theory in which nanoprotrusions were formed because of the interference between the incident laser and the excited surface electromagnetic waves caused by the presence of structural defects $[21,22]$. This theory can be also used to explain the formation of nanoprotrusions on the surface of the Ni-Co alloy coating. Moreover, after laser irradiation, vaporization and redeposition of the nanoparticles should also affect the surface nanostructures. However, the detailed mechanism underpinning this behavior requires further investigation [23]. When the applied laser power was greater than $0.22 \mathrm{~J} / \mathrm{cm}^{2}$, the Ni-Co alloy coating underwent rapid fusion due to extreme heat. Therefore, the surface morphology of the laser-processed area became smooth, and the nanoprotrusions on the surface almost all vanished.

3.2. Nanotribological Properties under Different Bias Voltages. Figure 3 showed the different relationships between the frictional force and normal load at bias voltages of $0 \mathrm{~V}, 0.5 \mathrm{~V}$, $1.0 \mathrm{~V}, 1.5 \mathrm{~V}$, and $2.0 \mathrm{~V}$. It can be seen that the friction increased quasilinearly with increasing normal load for the different Ni-Co alloy coating surfaces.

In Figure 3(a), for unprocessed specimen, the friction force with a forward bias voltage was larger than that without a bias voltage. Its friction forces can be changed more than 2 times under the different external electric field. However, the situation was reversed in Figures 3(b), 3(c), and 3(d). This difference in the frictional forces was mainly due to changes in the surface crystal lattice and texture that can influence the friction between metal friction pairs [24]. It may be concluded that the bias voltage can be increased to reduce friction on the surface after laser processing. In particular, the friction force under a bias voltage was significantly reduced (Figure 3(d)). Its friction forces changed more 


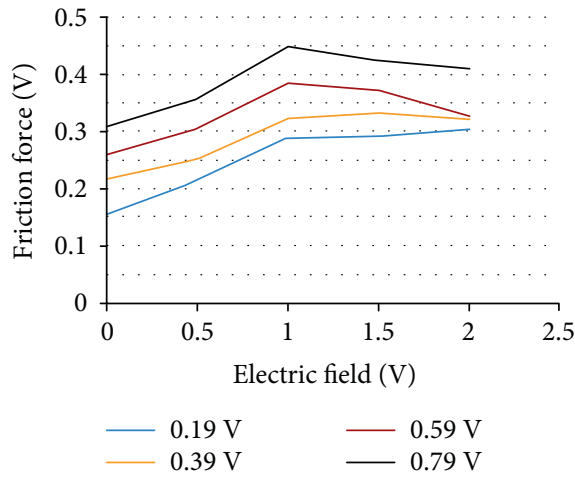

(a)

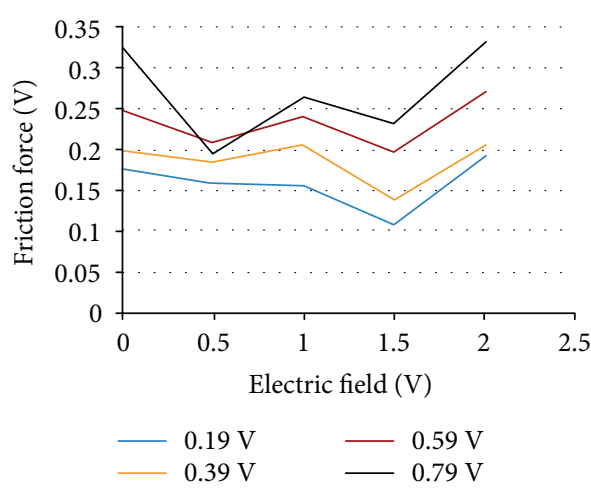

(c)

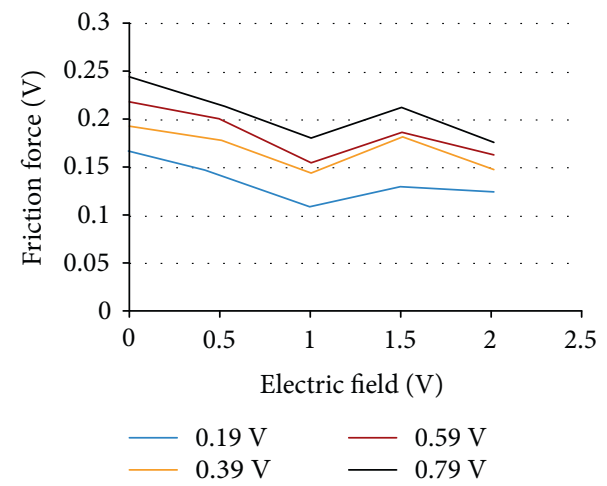

(b)

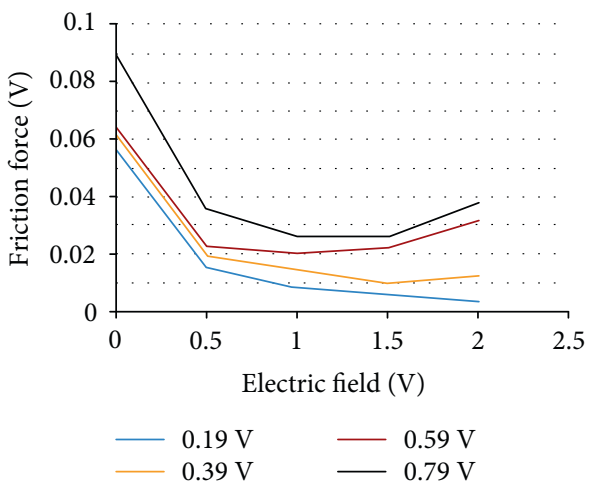

(d)

Figure 4: Frictional force versus bias voltage, from $0 \mathrm{~V}$ to $2 \mathrm{~V}$, at four normal loads $(0.19 \mathrm{~V}, 0.39 \mathrm{~V}, 0.59 \mathrm{~V}$, and $0.79 \mathrm{~V})$ for the four Ni-Co alloy coating surfaces. (a) Unprocessed; laser processed at (b) $0.03 \mathrm{~J} / \mathrm{cm}^{2}$; (c) $0.05 \mathrm{~J} / \mathrm{cm}^{2}$; (d) $0.18 \mathrm{~J} / \mathrm{cm}^{2}$.

than 12 times for this specimen. Therefore, the nanotribological properties were affected by laser irradiation under a forward bias voltage.

Figure 4 showed the relationship between frictional force and the bias voltages of $0.0 \mathrm{~V}, 0.5 \mathrm{~V}, 1.0 \mathrm{~V}, 1.5 \mathrm{~V}$, and $2.0 \mathrm{~V}$ with four normal loads $(0.19 \mathrm{~V}, 0.39 \mathrm{~V}, 0.59 \mathrm{~V}$, and $0.79 \mathrm{~V})$. The frictional force could be controlled by external electric field. In Figure 4(a), the frictional force initially increased with increasing bias voltage but then decreased while the bias voltage exceeded $1.0 \mathrm{~V}$ at normal loads of $0.19 \mathrm{~V}, 0.39 \mathrm{~V}, 0.59 \mathrm{~V}$, and $0.79 \mathrm{~V}$. However, the frictional force initially decreased with increasing bias voltage and then increased as shown in Figures 4(b), 4(c), and 4(d). The trend varied, mainly due to the changes in the surface crystal lattice and texture [25].

There are two main theories which may be used to interpret these behaviors: electrostatic interaction theory and self-generated voltage theory. Electrostatic interaction theory dictated that the external electric field can influence the electrostatic force between friction pairs and thus affects the real normal load $\left(P_{\text {real }}\right)$. The sphere-plane electrostatic adhesion force $\left(F_{e}\right)$ is related to the voltage of the external electronic field $(U)$. When the bias voltage exceeds $0 \mathrm{~V}$, the real normal load initially decreases with increasing bias voltage and then it increased, which matched the measured results. Self-generated voltage theory said that during the repeated relative movement of the tip and sample surface, the friction between metal friction pairs would self-generate a voltage $V_{g}$ [24-26], the direction of which might be contrary to the external electric voltage $V_{e}$. Thereinto, the self-generated voltage $V_{g}$ increases as the number of repeating relative movements between the tip and sample surface increases [25]. Thus, the actual bias voltage $V_{a}$ between tip and sample surface is $V_{a}=V_{e}-V_{g}$. After laser treatment, the changes in the surface crystal lattice and texture affected the rate of increase of $V_{g}$. This trend is reversed after laser irradiation, because of the differing rates of increase of $V_{g}$ and $V_{e}$.

\subsection{Nanotribological Properties of Different Nanotextures.} Figure 5 showed the variation in friction force and normal load for different sample surfaces (unprocessed and processed at $0.03 \mathrm{~J} / \mathrm{cm}^{2}, 0.05 \mathrm{~J} / \mathrm{cm}^{2}$, and $0.18 \mathrm{~J} / \mathrm{cm}^{2}$ ). Figure $5(\mathrm{a})$ showed a plot of the frictional force versus normal load at the same bias voltage $V_{e}$ of $0 \mathrm{~V}$. According to the comparison of the sample before and after laser processing, the differences between the trends were not clear. A plot of the frictional force versus normal load at the same bias voltages $V_{e}$ of $0.5 \mathrm{~V}, 1.0 \mathrm{~V}$, and $2.0 \mathrm{~V}$ were shown separately in Figures 5(b), 5(c), and 5(d). When the bias voltage exceeded $0 \mathrm{~V}$, the differences between the changing trends of the surface friction force become distinct: after laser processing, the surface friction was significantly lower than before. Thus, the frictional force can be controlled through the use of laser processing under a forward bias voltage. In Figure 5, as the surface became smooth after laser processing 


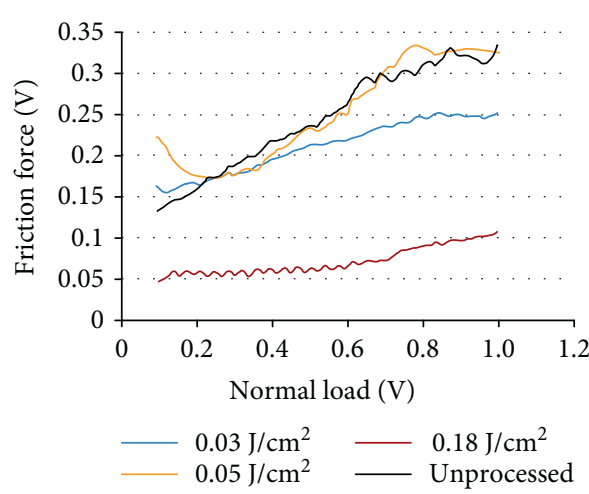

(a)

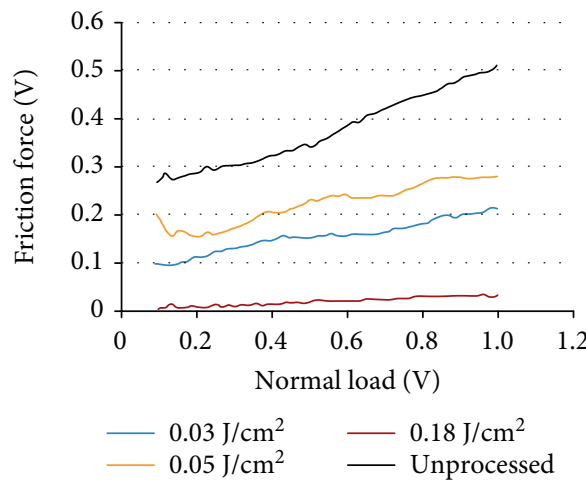

(c)

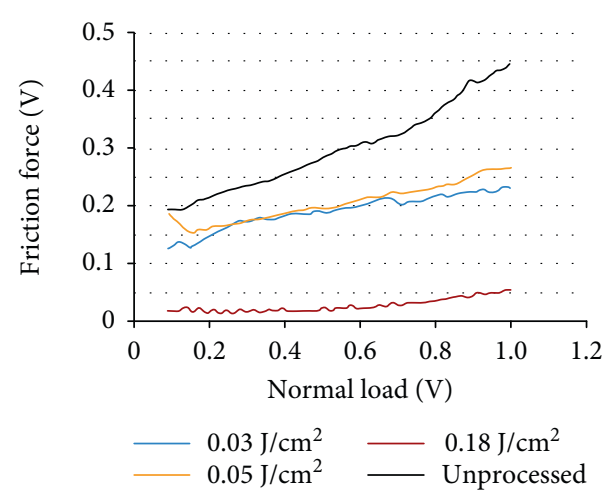

(b)

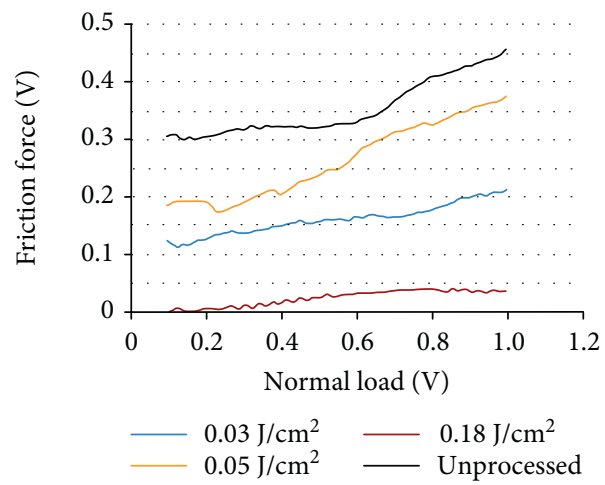

(d)

FIGURE 5: Frictional force versus normal load for the different sample surfaces under four constant bias voltages. (a) $0 \mathrm{~V}$; (b) $0.5 \mathrm{~V}$; (c) $1.0 \mathrm{~V}$; (d) $2.0 \mathrm{~V}$.

at $0.18 \mathrm{~J} / \mathrm{cm}^{2}$, the frictional force changed between approximately between $0.05 \mathrm{~V}$ and $0.1 \mathrm{~V}$ under a bias voltage of $0 \mathrm{~V}$ and varied between $0 \mathrm{~V}$ and $0.05 \mathrm{~V}$ when the bias voltage exceeded $0 \mathrm{~V}$. To some extent, the frictional force remained stable. Therefore, under an external electrical field and specific laser processing, the Ni-Co alloy surface frictional force can be controlled so as to be reduced by the nanotexture deposited on the Ni-Co alloy coating.

\section{Conclusions}

This paper presented a simple, easily controlled laser processing method for fabricating regular nanotextures on the electrodeposited Ni-Co alloy surface. The electronic controlling on the friction performance of the nanotexured surface was achieved using atomic force microscope. Regular nanoprotrusions can be produced by choosing certain laser processing parameters, and the frictional force on such nanotexured surfaces can be controlled by an external electric field. Before laser processing, the friction initially increased with the bias voltage and then decreased after the bias voltage exceeded 1.0 V. Its friction forces can be changed more than 2 times under the different external electric field. After laser processing, the trend of the frictional force was reversed and its friction forces changed more than 12 times for the laser-processed sample with $0.18 \mathrm{~J} / \mathrm{cm}^{2}$ laser power. Furthermore, with certain nanotextures and bias voltages, the frictional force could be maintained at a stable value.

\section{Nomenclature}

$P_{\text {real }}:$ Real normal load $[\mathrm{N}]$

$F_{e:} \quad$ Electrostatic adhesion force $[\mathrm{N}]$

$U: \quad$ External electronic field [V]

$V_{g}$ : Self-generate a voltage $[\mathrm{V}]$

$V_{a}: \quad$ Actual bias voltage $[\mathrm{V}]$

$V_{e}: \quad$ External electric voltage $[\mathrm{V}]$.

\section{Subscripts}

MEMS: Micro-Electro-Mechanical System

AFM: Atomic force microscope

SEM: Scanning Electronic Microscopy

FFM: Friction force microscopy

M: $\quad$ Mirror.

\section{Conflicts of Interest}

The authors declare that they have no conflicts of interest.

\section{Acknowledgments}

The authors acknowledge the Fundamental Research Funds for the Central Universities (Grant no. 2015QNA35) and the Priority Academic Program Development of Jiangsu Higher Education Institutions (PAPD) for supporting this work. 


\section{References}

[1] A. A. G. Bruzzone, H. L. Costa, P. M. Lonardo, and D. A. Lucca, "Advances in engineered surfaces for functional performance," Cirp Annals-Manufacturing Technology, vol. 57, no. 2, pp. 750-769, 2008.

[2] X. Fan, M. W. Little, and K. K. Murray, "Infrared laser wavelength dependence of particles ablated from glycerol," Applied Surface Science, vol. 255, no. 5, pp. 1699-1704, 2008.

[3] J. X. Man, H. F. Yang, Y. Q. Wang, C. Yan, and S. Zhang, "Nanotribological properties of nanotextured Ni-Co coating surface measured with AFM colloidal probe technique," Journal of Laser Micro/Nanoengineering, vol. 12, no. 1, pp. 16-21, 2017.

[4] X. Fan, S. Z. Wang, A. L. Zheng et al., "Investigation on infrared laser desorption of solid matrix using scanning electron microscope and fast photography," Microscopy Research and Technique, vol. 76, no. 7, pp. 744-750, 2013.

[5] I. Etsion, O. Levinson, and G. Halperin, "Experimental investigation of the elastic-plastic contact area and static friction of a sphere on flat," Journal of Tribology, vol. 127, no. 1, pp. 47-50, 2005.

[6] K. D. Zhang, J. X. Deng, R. Meng, P. Gao, and H. Yue, "Effect of nano-scale textures on cutting performance of $\mathrm{WC} / \mathrm{Co}-$ based Ti55Al45N coated tools in dry cutting," International Journal of Refractory Metals and Hard Materials, vol. 51, pp. 35-49, 2015.

[7] H. S. Amoli, H. Amani, and M. Mozaffari, "Deposition of ITO nanopowder layers on flexible substrate by spin coating using pulsed Nd-YAG laser for crystallization and bonding," Journal of Russian Laser Research, vol. 34, no. 6, pp. 581-585, 2013.

[8] R. Ghasemi, R. Shoja-Razavi, R. Mozafarinia, and H. Jamali, "The influence of laser treatment on thermal shock resistance of plasma-sprayed nanostructured yttria stabilized zirconia thermal barrier coatings," Ceramics International, vol. 40, no. 1, pp. 347-355, 2014.

[9] H. F. Yang, H. D. He, E. L. Zhao et al., "Electronic-controlling nanotribological behavior of textured silicon surfaces fabricated by laser interference lithography," Laser Physics Letters, vol. 11, no. 10, article 105901, 2014.

[10] H. F. Yang, H. D. He, E. L. Zhao et al., "Simulation and fabrication of nanostructures with laser interference lithography," Laser Physics, vol. 24, no. 6, pp. 225-292, 2014.

[11] H. F. Yang, T. C. Chen, J. G. Qian et al., "Friction-reducing micro/nanoprotrusions on electrodeposited Ni-Co alloy coating surface fabricated by laser direct writing," Bulletin of Materials Science, vol. 38, no. 1, pp. 173-181, 2015.

[12] J. Bico, C. Marzolin, and D. Quéré, "Pearl drops," Europhysics Letters, vol. 47, no. 2, pp. 220-226, 1999.

[13] X. Zhang, F. Shi, X. Yu et al., "Polyelectrolyte multilayer as matrix for electrochemical deposition of gold clusters: toward super-hydrophobic surface," Journal of the American Chemical Society, vol. 126, no. 10, pp. 3064-3065, 2004.

[14] N. J. Shirtcliffe, G. McHale, M. I. Newton, G. Chabrol, and C. C. Perry, "Dual-scale roughness produces unusually waterrepellent surfaces," Advanced Materials, vol. 16, no. 21, pp. 1929-1932, 2004.

[15] Y. Y. Wu, H. Sugimura, Y. Inoue, and O. Takai, "Thin films with nanotextures for transparent and ultra water-repellent coatings produced from trimethylmethoxysilane by microwave plasma CVD," Chemical Vapor Deposition, vol. 8, no. 2, pp. 47-50, 2002.
[16] Y. F. Mo, W. J. Zhao, D. M. Huang, F. Zhao, and M. Bai, "Nanotribological properties of precision-controlled regular nanotexture on H-passivated Si surface by current-induced local anodic oxidation," Ultramicroscopy, vol. 109, no. 3, pp. 247-252, 2009.

[17] Y. F. Mo, Y. Wing, J. B. Pu, and M. Bai, "Precise positioning of lubricant on a surface using the local anodic oxide method," Langmuir, vol. 25, no. 1, pp. 40-42, 2009.

[18] J. Y. Park, Y. Qi, D. Ogletree, P. A. Thiel, and M. Salmeron, "Influence of carrier density on the friction properties of silicon pn junctions," Physical Review B, vol. 76, no. 6, article 064108, 2007.

[19] Y. Qi, J. Park, B. Hendriksen, D. F. Ogletree, and M. Salmeron, "Electronic contribution to friction on GaAs: an atomic force microscope study," Physical Review B, vol. 77, no. 18, article 184105, 2008.

[20] H. Liu, S. Fujisawa, A. Tanaka, and Y. Enomoto, "Controlling and improving the microtribological properties of LangmuirBlodgett monolayer films using an external electric field," Thin Solid Films, vol. 368, no. 1, pp. 152-156, 2000.

[21] J. Koch, F. Korte, T. Bauer, C. Fallnich, A. Ostendorf, and B. N. Chichkov, "Nanotexturing of gold films by femtosecond laser-induced melt dynamics," Applied Physics A, vol. 81, no. 2, pp. 325-328, 2005.

[22] P. T. Mannion, J. Magee, E. Coyne, G. M. O'connor, and T. J. Glynn, "The effect of damage accumulation behaviour on ablation thresholds and damage morphology in ultrafast laser micro-machining of common metals in air," Applied Surface Science, vol. 233, no. 1-4, pp. 275-287, 2004.

[23] W. Jia, Z. N. Peng, Z. J. Wang, X. Ni, and C. Y. Wang, "The effect of femtosecond laser micromachining on the surface characteristics and subsurface microstructure of amorphous FeCuNbSiB alloy," Applied Surface Science, vol. 253, no. 3, pp. 1299-1303, 2006.

[24] R. Chen, W. Zhai, and Y. Qi, "The mechanism and technology of friction control by applying electric voltage II. The effects of applied voltage on friction," TRIBOLOGY-BEIJING, vol. 16, no. 3, pp. 235-238, 1996.

[25] W. Zhai, R. Chen, and Y. Qi, "The mechanism and technique of friction control by applied voltage I. The correlation of selfgenerated voltage to friction force," TRIBOLOGY-BEIJING, vol. 16, no. 1, pp. 1-5, 1996.

[26] H. R. Ao, Y. F. Gao, W. J. Zhai, and Y. L. Qi, “An experimental research on self-generated potential of ball-disc friction pair under normal pressure and low and middle vacuum," TRIBOLOGY-BEIJING, vol. 19, no. 250, pp. 250-254, 1999. 

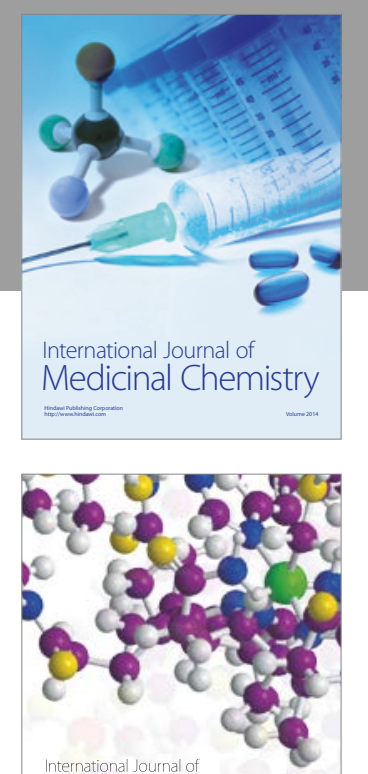

Carbohydrate Chemistry

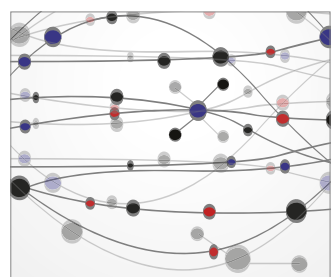

The Scientific World Journal
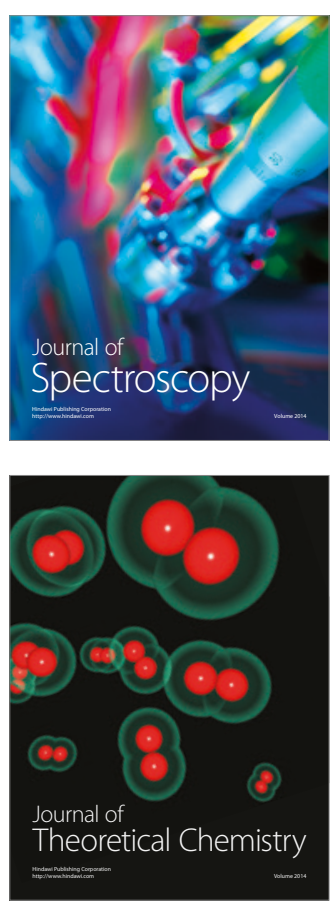
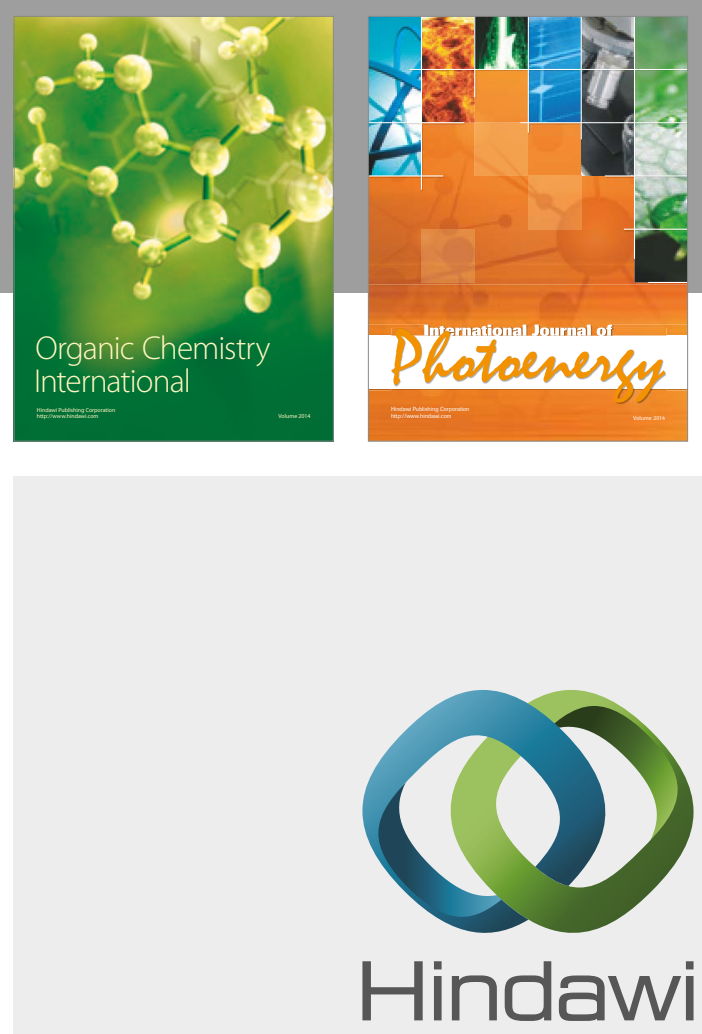

Submit your manuscripts at

https://www.hindawi.com

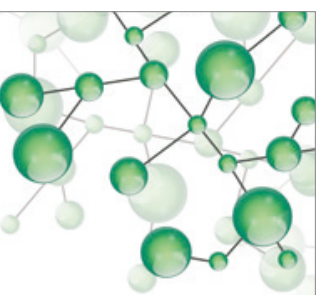

International Journal of

Inorganic Chemistry

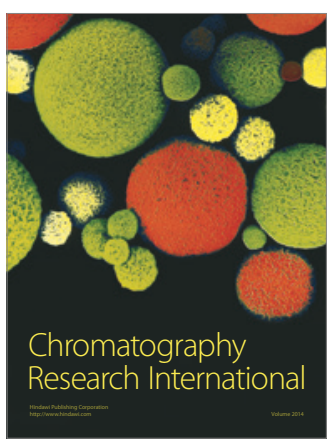

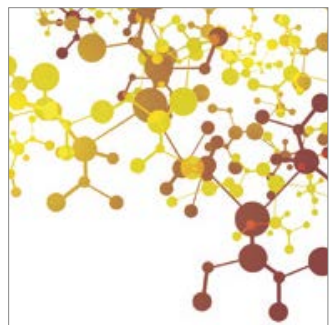

Applied Chemistry
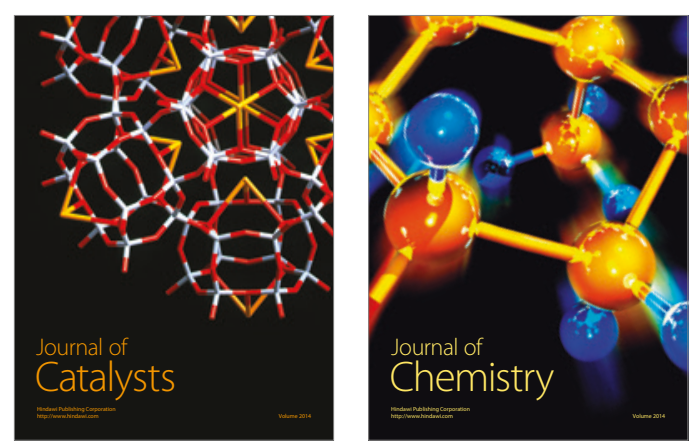
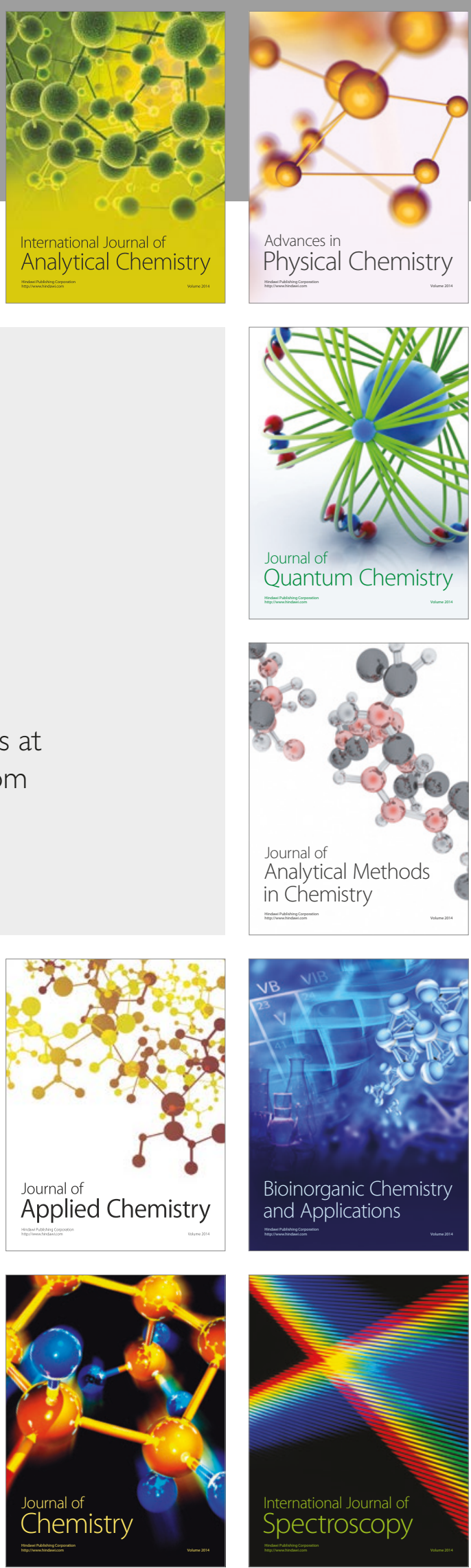